\title{
TWO INTERVIEWS WITH KEN THOMPSON
}

\author{
September 27, 1980 in Linz, Austria \\ June 27, 1996 in Maastricht, The Netherlands
}

[Ken Thompson has granted two interviews to Jaap van den Herik. The first one took place 16 years ago during the $3^{\text {rd }}$ World Computer Chess Championship, the second one during the $8^{\text {th }}$ Advances in Computer Chess Conference in 1996. The text reported below is a transcript of a tape recording. The 1980 interview has been condensed to what is relevant in relation to the 1996 interview. A full account has been published as Appendix E in Computerschaak, Schaakwereld en Kunstmatige Intelligentie (Van den Herik, 1983). The interviewer's queries have been italicized. Ken Thompson's responses appears in Roman type. The interviews are preceded by some background details.]

\section{A Short Curriculum Vitae}

Date of birth

Education

Profession

Program

Working with chess programs

Familiarity with chess

Strength of play

Main professional results

Award of Honour

\author{
$4^{\text {th }}$ February 1943. \\ M.Sc. from University of California, Berkeley, CA., in Electrical \\ Engineering. \\ Working at Bell Laboratories. \\ BELLE. \\ Since 1973. \\ I do not play chess, I know the rules. \\ Maybe about 1500 , but I do not play. \\ 1970s Development of C. \\ Development of UNIX. \\ 1980 BELLE World Computer Chess Champion. \\ 1980s Development of 4- and 5-piece endgame databases. \\ 1983 Recipient of the minor Fredkin Prize. \\ 1983 Recipient of the Turing Award (with D.M. Ritchie).
}

\section{THE FIRST INTERVIEW}

Linz, Austria, September 27, 1980

Can you tell something on your activities in the field of chess programming?

"In 1973 I made a software-only chess program and competed in Atlanta in the 1973 ACM Tournament, came in dead center of the pack, won one, lost one, and drew two. In 1974 I took the program to San Diego and tied for the second place, I think, with three wins and one loss. I then stopped and made the first chess machine, shortly before the World Championship in Toronto. I took the first chess machine to Toronto and tied for the third place, or something like that. That was the only appearance of that chess machine. After that I made a much bigger chess machine, very similar to the BB chess machine, now, here at this tournament, and took it to Washington DC, to the 1978 ACM Tournament. I won the tournament with remarkable luck, I had a great win over CHESs 4.9 and in the last round a spectacular game against a weaker program, one of the still talked-about games. So, it was remarkable but lucky."

"I rated that program in the subsequent year, to find out how good it was, and its rating was consistently lower than CHESS 4.9's. So I realized how lucky it really was. In Detroit, for the 1979 ACM Tournament, I took the same program, I had not changed it a bit from the 1978 version. It had an unlucky draw against CHAOS and a lucky draw against CHESS 4.9 and it finished half a point down from CHESS 4.9 , taking second. Since then we have been designing a new chess machine, which is much faster - we had learned from the old one. Since February we have been building it with extreme efforts. We got it running about a month ago, maybe a little more.

"Since it is been running well, we have been taking it around and trying to get experience with it. It probably is the best in this tournament, but you know luck plays a major role." 
What do you think is your own playing strength?

"I do not know. It is a strange kind of experience you will not find with chess-players, in that I can analyse and appreciate grandmaster games, but with absolutely no chess experience from playing myself. It is a strange combination of strong, but totally unexperienced and clumsy. I would expect this combination to rate about 1500 in the United States."

How strong do you think the strongest program is rated now?

"I know that the highest actual rating is to be 2050."

Have you ever played seriously against a program?

"No, I never played with clocks. I have sat down and tried to play the program in a serious way, making up my mind when I wanted to make it up, not with clocks. I got beaten always."

What do you consider as passed milestones in the field of computer chess?

"The first one has to be computers, which I guess is by Von Neumann. The second one has to be computer chess which is Shannon. There are some historical pre-examples, but I do not think they are important. Then Greenblatt has to be credited with showing that computers can play chess and for a very long time in that era it was a hard problem that no-one wanted to start on; a hard problem that could not be done, it is a waste of time. Next was Fischer and as near as I can tell all the strong players right now are in because of the excitement of Fischer caused around 1972 and 1973 when I got in for example. I think that his excitement in the game of chess, in the United States, especially, got everyone. I mean, if you look at when these people became involved it was during the Fischer era. The programs that are strong now are all Shannon-A programs. The first program to really say that Shannon-A is possible was TECH. I think that is an important milestone. Then of course, CHESS 4.9 is very important; it had several advances."

What do you consider milestones in the field of Artificial Intelligence?

"I have never used the word 'Artificial Intelligence'. I deflect the question or refuse to answer the question. I have built-in prejudices against the field of Artificial Intelligence."

\section{The Future of Chess}

When you look at computer chess, what do you think will be the result in the future?

"I have to bust it into Shannon-A and Shannon-B. The playing strength of Shannon-A will go up with the speed of computers, it is guaranteed. They will go up arbitrarily, above the level of the World Champion."

There must be a limit. To what strength can it go on? Is there a solution, I mean the game is finite, is not $i t$ ?

"Well, you are talking about extrapolations that are far beyond what we can expect that way. So the playing strength will get somewhere between grandmaster level and perfect play. I think that in the future it will just go through and on; and I do not think that computers will run into fundamental physical properties that will stop them in their playing strength. Computers in general will get bigger and faster, and bigger and faster, for a very long time."

When do you think, they will reach the level of the World Champion?

"It is very hard to predict. I predict much longer than anyone else. Most people are pushing numbers like ten and twenty years, I push a hundred years, a very long time. It requires new things that you cannot think of now in the field of computer architecture. You cannot predict when these things will come along, you just hope they will, so it is hard to predict."

What kind of thing does it require?

"Very, very low switching time, very small circuits, where you can perhaps code an atom or the spin of an atom to encode information and read those back in very low pico second time. Those are all physically possible things, but totally unthought of now."

So you think there can be an arbitrary raise?

"There are definite limits. As you said, in chess there are definite limits. Perfect play is obviously some asymptote that you can approach, but also in computers there are limits; the Heisenberg-uncertainty 
principle and the speed of light together will give you a limit of how fast it can be. But if you look at those numbers, they are so fast that it does not matter. If I now go back to Shannon-B. Shannon-B always has a hope of doing it better and faster and sooner, but there is no hope for Shannon-B. I do not want to sit around and say 'I do not know how to do it, no-one, I know, knows how to do it, but it will be done'. It is silly to do that. I have looked at the problem hard enough. They will not succeed."

Looking at the development of Shannon-A with the playing strength raising, do chess-players have respect for the programs?

"You find a mixture of feelings. You find true fear, I mean that for these people chess is what they do, chess is their livelihood, they base themselves on chess, and then they feel frightened in some way. Many of the very, very strong grandmasters feel this way. Others take the programs as toys, they feel contempt, they just do not care."

How do you know that some grandmasters feel threatened by chess programs?

"I have talked to them. Benkö for a while, especially since he is very heavy into the matter of chess problems and computers. I have had this letter discussion, not verbal discussions, with him on cooked problems, and the computer is, of course, always right. I could tell by this response that he felt very threatened by computers."

Do you yourself have respect for the playing strength of computers?

"I treat it differently, I do not relate it to chess, it is different. I only go out into the human chess world with computers for the purpose of finding a measure of what I have done. The chess world has nothing to do with my work. I am doing it for fun."

\section{The Acceptance of Computer Chess}

What kind of role do you think computer chess should be allowed to play in the chess world?

"Very recently the USCF has made some funny rules for computer chess."

Do you think computers should be allowed to enter normal tournaments?

"I can answer the question from my point of view and from their point of view. They would be utterly silly not to allow computers because computers are big draws. Deep down I think it is a human game. When someone packs up and goes to tournament in a weekend, he expects to sit across from a human and play a human. When he is tired on the third day of this tournament, after six rounds he expects the opponent across from him to be tired. He expects to blow smoke in his face and get him upset, all these kind of things are issues in human games. Playing chess is unnerving I have seen people who cannot even hold a piece, because they are so nervous.

"In the United States chess is not a big deal, on the whole. It should be, there is no reason why it could not follow Europe or even Eastern Europe and become quite a big deal. All it needs is publicity, push and recognition, and computers certainly provide publicity, push and recognition. I think they would be silly not to use computers as a tool to obtain their own goals of spreading chess and popularizing it.

"I am going to find out whether it is allowed to play in these tournaments. I think I am going to play in an international tournament. FIDE is very, very reluctant to prejudge, you cannot go to them and ask them whether or not they will allow computers, they will not say anything. You have to present them with the problem before they say anything. In the spring, I am going to enter in an international Round Robin tournament, for the purpose of generating norms in the United States. We do not have any hope to win or anything like that, but we hope to get a FIDE rating. If I get a FIDE rating, it will be submitted to FIDE, and they will have to make a decision."

Should computers be allowed to participate in the national team?

"The programs are not yet that good, and they will not be good for years and years and years. It is not a problem, we will be facing in the near future. I think that if computers really start to threaten human chess ... . It is a sport, what would be the purpose? Over a long, long time when computers are very, very good, what would be the purpose of having a chess olympiad where every country submits five computers and you have a big computer-chess tournament. Then because they are all comparable you just sort of flip a 
coin and some country, say Zaire, is appointed the World Champion for the next few years, whatever the cycle is and then it all happens again. Is not that kind of silly?"

In a few years' time, when the computers are better, they maybe can play in zonal tournaments. Do you think that would be a good idea?

"No. I think when they are rare and noteworthy, they should be allowed in tournaments, because they serve everyone's purpose. I mean it is the cutting edge; the best program and the best computer is going out there, they learn something if it is good competition. And also the chess world gets something out of it. I think, it is symbiosis; I think it should happen. But when computers are common and strong, neither gets anything out of it. When the computers play at a certain high level they should just be banned and everyone goes on as usual."

If you enter just one computer in a competition of, say, eighteen participants, do you think that affects the existence of chess as a profession?

"No, it is just a small world, it will not affect anything."

\section{Using Computers for Preparation Analysis etc.}

Do you think chess-players will use computers for preparation analysis?

"Yes, but for their data-processing abilities, not for their chess-playing abilities. I think that chess-players will look at a database opening position, at endgames, or at those kind of things, such as who plays what. A database application on your opponent giving some perspective of your opponent's play would be very, very powerful as a preparation tool."

And for endgame reviews too?

"Yes, for some endgames, but for those endgames which are rare enough, you can just forget it. I mean it is useful for endgames that are not instantly resignable; if you get Queen versus Rook, the man with the Rook resigns. So what good is it being able to tell him that it is a really harder game than it really is."

Do you think it is allowed to use a computer during the adjournments?

"I am a firm believer that you should not make rules that you cannot enforce. Therefore I think that you should allow computers in adjournments because you certainly cannot enforce that someone does not use computers during adjournments."

What do you think about using a computer for problem-solving competitions?

"Somehow I would think that that would be unethical, but also unenforcable. Unfortunately you will probably do an end to the current problem-solving type of competitions, unless they include good spattering of the kind of things that computers are not good at: the 'White-to-move-and-win' kind of problem-solving. It would be unethical to use computers, it is not in the spirit of the game, but you cannot enforce it. So I certainly have very strong feelings both ways."

And using computers in correspondence chess?

"I think people who play correspondence chess do it for fun. All the correspondence chess-players I know just love the game, they like to go home at night, instead of having a beer, they play over a couple of chess games. I think computers should be allowed as entities in correspondence chess under their own name. I also think that it is very similar to tournament chess in that there is not much benefit or reward or anything for someone who is weaker than a chess program to get access to a chess program and submit the moves. Basically what they are doing is running the chess program under their own name, and I cannot see any purpose for that from anybody's point of view. Stronger players may do some chess analysis with the program, but basically it is their own decision and I see nothing wrong with that."

If you look at the whole area of chess in which fields would you say no to the computer?

"They are tools like a pick and axe, if you want to dig a ditch pick and axe are good."

Can you anticipate the point of view of FIDE about the use of computers in the chess world?

"There is a political orientation, and that makes it very hard to predict what they will do. I think the rational decision is to allow computers provisionally for the novelty involved. It would make a big splash, I am sure 
it would help FIDE, it would help people who think they are good enough to get them into FIDE. That is rational, that is right, but I cannot predict what FIDE will do, no-one can.

"From the academic side there will be no problem, I think. There will be very few computers, there will be the leading edge of the computers and they will cause a sensation on both sides. It will be a good yardstick for measuring from the point of view of the computer people, how well they are doing in international chess. And from the point of view of the international chess: the publicity cannot be bad, when they are just creeping in, down at the bottom level they cannot be a competition and they cannot be a threat. I can see no safe argument against them."

\section{Possible Influence of Computer Chess on Chess as a Profession}

Do you think that the development of computer chess will have consequences on chess as a profession? "On a very long term: yes. It will destroy opening analysis, chess will turn into a memory game. Modern opening analysis has done that to a large extent but computer chess would do it to a much, much larger extent. But that is a very long term. Computer chess will make books look very much like telephone directions, just listing variations. For sure that is got to affect chess very gravely."

Do you have any idea why a person chooses chess as a profession?

"Oh yes; they are all insane. No, no. It is what you do well, what you enjoy. There is always a satisfaction, especially in chess, it is the ultimate kind of thing. They get and demand respect in their field, in a sense it should be, it is a horrible profession."

Do you think that in the future, someone choosing between chess as a profession and a normal university education, will be influenced by the existence of strong chess-playing computers?

"No, I think people do not sit down and plot their lives. I think they do what opportunities are placed before them in a very strange way. The computer's influence, if there is any, will be very slow with time. From the point of view of someone getting in or going out of chess - or going through these decision stages -, it will look like a constant, they will not see progress. The situation will exist and they will just play their lives out the way it falls in front of them, they will not sit down and say: "oh my God computers are here, I will be a banker'. If it is really no challenge anymore chess will cease to be a game, and then these decisions will not come up."

The consequences of what you say last is that chess as a profession will disappear.

"If computers become very, very strong at it, but there will not be a time when computers destroy chess, there will not be a revolution. The process will be slow and no-one will perceive the process going on from their point of view and so it will affect no decisions."

But if we look 100 or 150 years ahead could it then be that chess as a profession has disappeared? "It will be gradual and no-one will know it. It is like saying 'Think of all the unemployed plowmakers these days, these poor people who lost their jobs when tractors came along'. That is absolutely the same."

Do you think chess professionals should use the service of chess computers?

"I think they are silly to do it now. I think they could correct some moves in books, improve play in some very rare endgames, and correct parts in the endgame books. But that is extending chess microscopically, the analysis is already in books."

Do you think that in a competition between humans and strong computers, humans will study the play of computers?

"The answer is yes, but in a small way. I have gone over computer games with humans and done analysis of fairly strong humans. You see that a computer sometimes comes up with a very imaginative kind of play, that neither contestant in a human game over the same position would think of as either attack or defense. A human will see such new things, assimilate them into patterns and put them in their vocabulary, or even in their repertoire, and use them. And as more and more of these patterns come out, computers will have less and less to teach to humans. But computers, when searching for a move are truly original. Everthing they do is absolutely original in a way that is totally uninfluenced by other human play." 


\section{Possible Input of Chess-Players into Computer Chess}

Do you think that in the future there will be more co-operation between chess-players and computer specialists?

"They are hard to talk to, both ways. The communication gap is rather large between those two groups trying to teach chess professionals about computers and the other way around. I see the possibility for cooperation in the area, I mentioned before: databases on every chess game ever played, databases on looking up what "So and So" does in this kind of line, what kind of position does White get advantage out of this kind of line. These are things computers can do. That is what computer professionals do to make computers accessible to people who do not know anything about computers. That is what games are all about, that is what database management systems, information systems are all about, that is what we do, that is our profession. If it applies to chess professionals, sure that is our profession too. We can supply these kinds of application programs for chess professionals."

You do not think that chess professionals will make a step towards you in the future, for instance by being interested in evaluation functions or in program techniques or something like that?

"No, they will never get into that. There are certain individuals who are involved, but that is because chess strength is unrelated to everything. There is nothing you can correlate with chess strength, it is an independent quality of a human being. So, there is just no reason why a computer professional could not be a strong chess-player. They are not disjoint classes."

\section{Conceptual Background}

Do you think that the programmer of a chess program has to be a chess-player himself?

"No, but it helps tremendously. Programs are not just written, they have to be written and then tuned. It takes a fairly long time to get the most out of the techniques and the tuning involves playing chess at the level which the programs play at or even playing above their level. You know, they are beaten and find out why they were beaten. To this end expert analysis by chess-players is very, very important."

When we are talking about the best program at the moment, which level do you think the adviser of the programmer has to have?

"I guess a routine chess-player."

In the far-off future the best program will beat the World Champion, will not it?

"That is a threat that will never be executed. It will never happen because neither side has anything to gain. I believe in forces pushing things to happen things do not happen all by themselves. People have to work very hard at chess to push it and to do that you have to be motivated, you have to have a reason, a goal, something. A home market will not stand for a 2500 chess program, it has no purpose. There is no reason to make a program better than any advice that it could ever obtain. It is like writing the killer Tic-Tac-Toe program, no-one has ever written the killer Tic-Tac-Toe program, because there is no-one to play, there is no place to put it, there is nothing to learn, there is nothing to be gained, there is no challenge."

Which is the big difference between the thinking of computers and the thinking of man?

"It is hard to answer, because I do not know how human beings think and I am sure you do not. I know how computers "think" and I am sure that humans do not think that way. So, I do not see any similarities."

Do you think that computers could ever think according to the Turing-test?

"Yes, I think that the Turing-test is not a test of intelligence. I do not think a computer could ever drive a taxi-cab in New York City. I do not think a computer will ever be able to carry on a conversation as you and $\mathrm{I}$, in the sense that I can change the subject and you will track it, that will never happen. I am not sure why, it is just my intuition. I think that if you stick to the really rigirous syntax and a fairly restrictive subject computers might for a while if they obeyed questions, fool people that they are perhaps humans."

How about the example in chess that people could not distinguish human games from computer games, like you stated in the last ICCA letter?

"Let me give you that example in particular. I took those five games. My old chess program played all five games and I rated the games by how many of the moves my program thought were best moves. It 
segregated two sets of games: one class contained the games where something like $30 \%$ of the moves were best, and the other class where about 60 to $70 \%$ were best. Of course, there was one game in the high class and four in the low class. To me that was a very strong indication that the computer could tell really absolutely which one was the computer game."

Do you think that the computers will be able to make a problem composition?

"I started to write such a program and I do not think it is hard. You can solve "Mate in two" in - maybe conservatively - a hundredth of the second. That means that you can test your problems, you can do it by trial and error."

Why do you think that human beings cannot advance more deeply into chess? Is it because of their way of thinking, or is it because of the complexity of the game?

"I think that if you look at the human chess-playing ability, it follows the curve of any ability; it is a standard deviation from the normal curve. Chess is a game that cannot be solved by humans, but I can invent a harder game than chess. I can invent a game which is so hard that you will not even attempt to play it because you get no results at all and there is no reason to go on. It is in the range of games that are easy enough from the syntactic point of view. Returning to chess, there is nothing to push people on the top higher, they are on the top. And the people that are on the very top are quite unique in the sense that they have obviously got something no-one thought then. So, for people on the top there is no challenge really and they will stop unless that group gets populated and the competition pushes them higher. I suspect humans could reach a higher level."

So, if computers get stronger could they raise the level of the best human players?

"Yes, I definitely think that. People's way up could be pushed further up."

Do you think that the results reached in the field of computer chess are applicable to other fields?

"Very few other fields. I think the field is very narrowed to two-person zero-sum full-knowledge games."

FAMED FOR HIS CDROMS: 5 PIECES, 6 PIECES, AND ...

Ken Thompson, Guest of Honour, left his audio research for being among friends, providing them with an excellent talk.

Vaeshartelt, Maastricht, June 27, 1996.

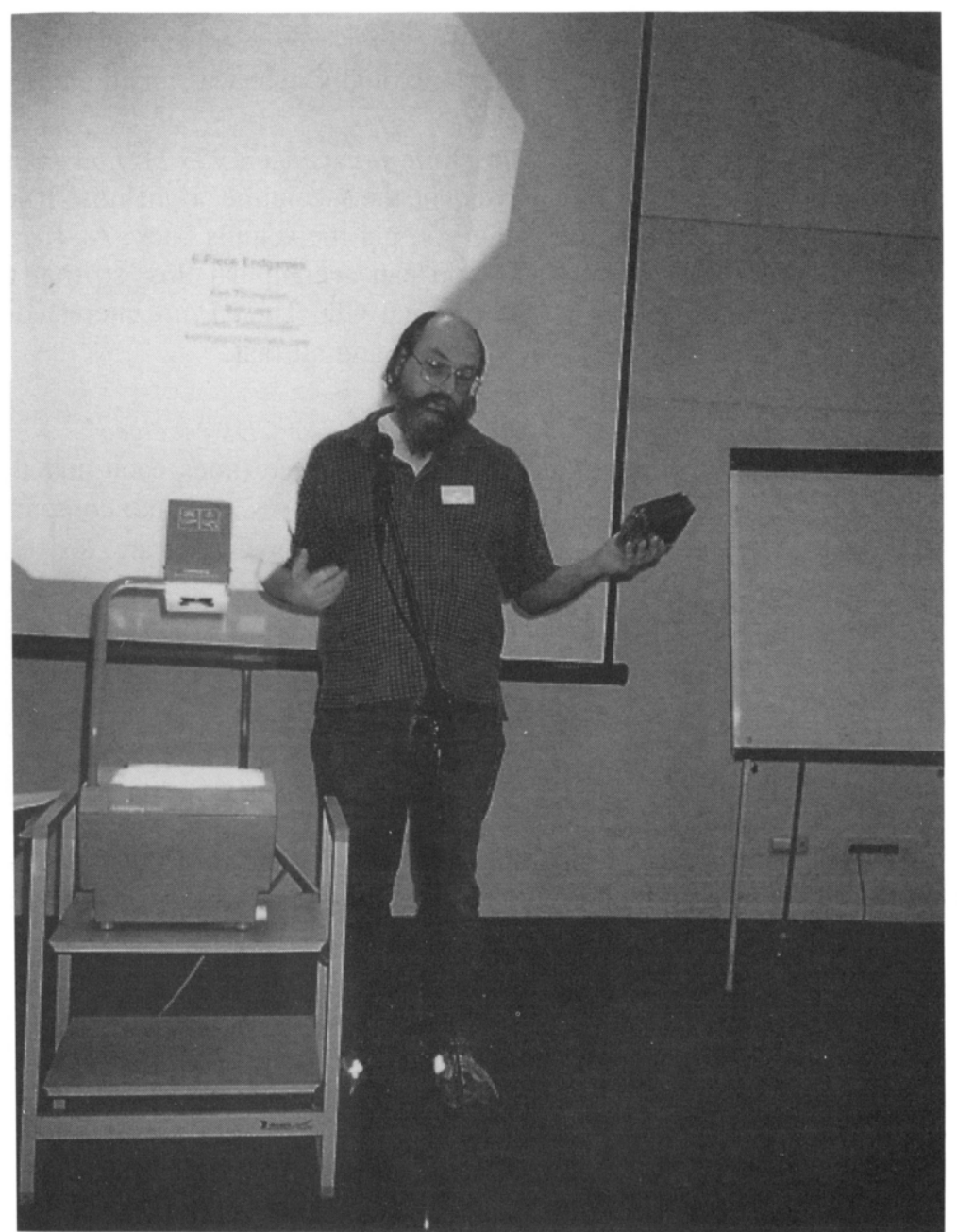


THE SECOND INTERVIEW

\author{
Maastricht, The Netherlands, June 27, 1996
}

What do you consider, since 1980, to be milestones in the field of computer chess?

"I believe threat analysis is about the only new thing: the null move. Everything else is just more of the same, or faster, or better; it is just normal technology. But the null move is the only thing that is really new."

What do you think of the playing strength of the best computers at this moment?

"I think the playing strength is less than the ratings given. I think it is about 2550, maybe higher, maybe 2575."

What has been your experience in computer-chess research after 1980?

"I just played my program BELLE in tournaments. I tried to give it a stable rating. I got a master rating and received the minor Fredkin prize for that. That was 1983. Then after that I did the 5-piece endgames and the CDs with the 5-piece endgames. I am currently working on 6-piece endgames. That is about all."

If we look in the fields outside computer chess, e.g., Artificial Intelligence in general, what do you consider to be milestones since 1980?

"Artificial Intelligence has not done anything since then. They have invented a new buzzword now and then, such as knowledge-based, neural nets, fuzzy logic, but nothing has happened."

\title{
And Software Engineering?
}

"Software Engineering is like any engineering. It is just an application of its sound principles. It is probably what software in early days was, wild and all, you know. Everyone did their thing. It is now more turned into a craft, and it is turning into a trade."

In 1983 you received the Turing Award for your contributions to Unix, C and BELLE.

"Belle was not mentioned. It was Unix and C that was mentioned."

Okay, my question was what have you done since 1983 besides the 5-piece endgames?

"I do not know exactly what I did in the meantime, right now I am working on digital audio compression. You cannot get the bits back, but you get the sounds back. And I am interested in CD, audio, stereo or five channels. At whatever bit rates you can accomplish this, so that the output is meant to be of CD quality which you cannot tell from the original $\mathrm{CD}$. Then I am interested in all variables, how well they do, how many bits per second you can transport and all that."

Let us return to computer chess. How are your CDs received?

"Very, very well. I repressed them two or three times each and then I stopped. I wrote to two companies and they are producing them now. One is Dormus, a Dutch company; and the other Chess-Base, the German company. They are now each producing their own software, so people can play through the lines. They are now competing with each other and, thus, the prices are dropping, which is nice. I got out of the business. I just gave away my last ones today [after the lecture on the first day of the ACC 8 Conference]. I have no more and I let commercial people do what they find interesting."

What are you going to do with the results of the 6-piece endgames?

"I am essentially in the same position, with the size of the machines and their enumerating power, as I was when I started the 5-piece endgames in 1984/1985. The size of the machine and the size of the entire technology group are comparable and so it is time to do 6-piece endgames. I am now very convinced that I can do a 6-piece endgame within just a couple of weeks. This is about what it took before to do the 5-piece endgames.

"What I am unsure of is whether I can be successful in doing something with the data, with the results. I am not sure if I can compress the results to fit in a CD, but I will definitely produce the data." 
What are you doing now with the data? Do you store them on gigabytes?

"Right now the 5-piece data is stored on optical discs. Our normal file system has optical disc backup. You can easily access things that are old or big. It just looks like it is online. Thus I have all 5-piece endgames online. The 6-pieces are too big for that and probably they will be on magnetic tapes for a while till I know what to do with them. Then I dump them either to $8 \mathrm{~mm}$ or newer CD ROM technology. Soon gigabyte CD ROM technology is coming out."

Looking to the future two possibilities can be seen. First, research goes on with seven pieces and, second, research goes on with Pawns.

"Pawns is like half a step. One Pawn is like half a step, and so probably, in 5 years, we will be able to do 6-piece endgames with one Pawn. And then in another five years we will be able to do the seven-piece endgames."

How about Pawns in the 5-piece endgames?

"I did all the one Pawns with the 5-pieces. The very first one was Queen and Pawn against Queen, and then Rook and Pawn against Rook. Now probably the 5-piece endgames are possible to do with two Pawns. It would be fun. There are a few good positions. There is much more food in 6-piece positions than in the two-Pawn-5-piece positions."

With two Pawns, it depends from which side you look at it. From the software side or computer-chess point of view. In chess, you remember, we wanted the result on the Timman-Velimirovic endgame. It was a twoPawn-and-4-piece endgame. It was interesting from a chess point of view and at that time we could do it heuristically with the machine. But with that method, it not an interesting endgame for you, you would say? "[laughter] It is kind of interesting. I am not sure that my temperament allows me to do something where I am really not sure of the answer. I think that I have to do it from first principles, the 6 pieces with the two Pawns."

Yes, it was two Pawns, a Rook, a Bishop, and two Kings. The two Pawns were blocked One Pawn was on $a 2$ and the other was on a3.

"Yes, yes. My guess is to do that will probably not be within 10 years. People doing that have nine years to go."

\section{The Future of Chess}

Back to the playing strength of computer programs. How strong do you think they will be in the future?

"It is a long time when there will be a strongest program. I think they will get stronger and stronger for ever."

When will they surpass the level of the World Champion?

"I think about 2020 to 2030."

Why that long?

"Everyone gets excited when there is a new machine. And true, that is a big step, that is like the one step that occurs every 10 years. And there is not going to be another step for another 10 years at least, I mean. You understand my point? Everyone gets excited at the beginning, right now, because it looks like fast progress when there is a new machine out. But it takes a long time before a new machine comes out. The progress from 1983 till now has been faster than average because the progress is exploded into a couple of dimensions of the technology curve. A World-Champion program is a sort of super-human kind of work. I do not think that the commercial atmosphere will support progress in chess in the future. And so the jump in technology that is made and is going to be in LSI will slowly erode as normal technology overtakes it.

I think it is probably going to be around the year 2005 that regular microcomputers (the chips, I mean the regular general-purpose CPUs) will surpass the special-purpose machines. They become equal and then there will be another generation after that before they carry on and start pushing the World Champion."

But computers now only need to bridge an ELO gap of 200 to 300 points.

"Yes, but I think that is much harder, much harder, now. It was 200 Elo points per ply; that is not holding up. It is probably less than 100 points per ply now. Computers are just going in a new technology and I think the current ones are going around 12 ply. I think they probably have to go to 14 or 15 ply to take the 
World Champion title. They need a full generation of the speed they have now, and I think that is two generations of microcomputers at least."

Let us have a look at what I asked you 16 years ago. There was the future of chess. I had a question then: Do you think that chess-players feel threatened by chess programs?

"If one is near the playing strength of strong programs, one feels threatened anyway. Chess programs tend to play slightly stronger than their strength. I mean when they play humans, they play a little stronger than they are. It is always the case. If they are 1200 they will play like 1400 . Programs that are 1400 , will play like 1600. And that is why people feel threatened. Now the strength is close to the super grandmaster range and so they will feel threatened. Grandmasters are starting to feel like they have been taken over and the low super grandmasters are the ones that are complaining about the conditions, and lights, and all."

\section{The Acceptance of Computer Chess}

16 years ago I also asked you whether you thought computers should be allowed to enter normal tournaments. Can you say again something on this topic. [Thompson starts reading the old interview] "My answer is about the same. As long as there is a symbiosis it should be allowed. As long as we do something for them and they do something for us. As soon as it turns purely commercial or if there is nothing to be gained then there is no reason to enter tournaments. If computers become very strong they should not be allowed. They should not be allowed in class tournaments where they have a chance of winning."

Not?

"No. There is nothing to be gained. But when entering a tournament in which their playing strength is in the center, everybody will understand the reason, and all the participants may understand what is happening, so that they can actually contribute to something like publicity or prize-money or whatever. Then, yes they should be allowed. They should be welcomed."

What about participating in the Olympiad?

"No, the Olympiads are special. A special kind of thing. Maybe an Olympiad team with computers that might be an extra option, for instance, from the ICCA."

"Yeah, and then because of publicity. I think that everybody will get something out of it, especially if they do not have a clear win. There are still powerful teams. All the ex-Soviet grandmasters now spread out and there are a lot of teams with a lot of very strong players. That will be fun. If they allow it, I think it will be great."

We also spoke about postal chess.

"Whether they should be allowed? I think that they should just make up the rules that they are either allowed or not and live by the rules. But if they disallow computers in postal chess it is hard to check it. It is like saying you cannot have books in postal chess. It is something you can never enforce. Probably you allow it, because you cannot disallow it."

\section{Possible Influence of Computer Chess on Chess as a Profession}

I have also some questions on the possible impact of computer chess on chess as a profession. You said already that the weaker grandmasters now are threatened by the programs. Could the playing strength also influence the young players' attitude towards their aiming at a chess profession or a chess career.

"I do not know. So far, it does not seem to be the case: I mean there is a whole bunch of new grandmasters, such as Anand and Kramnik and Kamsky who have grown-up with computers. The older grandmasters, like Bronstein here, talked about the young ones with all their databases and if anything has helped, then computers have developed their skills and their organisational abilities, especially in the openings and endgames. Receiving games and distributing games have become real scientific and professional work to chess-players." 
So, you state that the impact is positive. The new grandmasters take all the positive effects from computer chess and they now play even stronger than before and are better organized.

"Yes, I think so. I also think that when computers start playing near the World-Championship level the publicity will be very strong, such as in the Philadelphia match, and this publicity will actually bring people in. You know, just like Fischer or Kasparov."

\section{Possible Input of Chess-Players into Computer Chess}

Our discussion on the relation between chess-players and computer chess is more on the publicity side. But how about the programming side? You yourself never worked with chess masters or grandmasters. Did you not do a bit of work with Mike Valvo?

"Yeah, I worked with Valvo. Valvo was the strongest person I worked with on a regular basis. He was a weak IM, strength maybe 2450."

Do you think that it is necessary nowadays to work with grandmasters to have a good program? DEEP BLUE, for instance, has a grandmaster involved in the programming activities.

"I think if they are going to play serious tournament chess than they have to have opening preparation and I think they need a good theoretician, not a good player but a good theoretician, to do that. A strong chess player will also help in post mortem analysis of structural problems"

\section{Conceptual Background}

What do you think is the most important thing for a successful chess programmer?

"You just should have a broad systems kind of background. You have to have a mental outlook. If you are going to get serious you have to cultivate relationships in the chess community, get yourself invited to tournaments and play in those tournaments to give something back to the tournaments. Do not just go with the idea of winning the tournament. You have to cultivate it and that takes you a lot of work and also, a lot of commitment, and a lot of time. It is a full-time job at least."

How much time of your life did you spent on computer chess?

"When I was very active, I probably spent nearly every waking hour for years. Especially the preparation of events was interminable. I probably got 6 hours sleep and all the rest of the time I was studying and preparing my program for the tournaments and the games. I knew exactly what every player was going to play, I knew exactly every book line, I knew everything."

Even so you had to play a play-off in Linz was not it?

"Yes, I did. I got a draw in the tournament. It was some sort of Bishop's game. With the Bishop opening, I was Black and I looked at the position, I still do not understand that position. I thought the computer was much, much better. It just did not go in. It did not go for the throat."

And after the World Championship you worked till 1983 also together with Joe Condon?

"Yes, I did. We worked on the same machine. We crossed lines but that is a gross characterization."

And in 1983 it went wrong.

"In 1983 I got had by an algorithm. I had this beautiful time-control algorithm that counted extensions. I do not know how to describe it but I just got seduced into believing this thing played better and it did not. It solved problems better, but it played worse. I never really played it against BELLE-OLD on the machine and I should have.

"I did not do it, because I would have to swap micro-code in order to get it to play one side, and then play the other side. I did not do it and I should have. I played probably 200 points worse. But it solved problems. [laughter] And in experiments in the laboratory it even got, on the Bratko-Kopec tests, the highest score that anyone so far has reached." 
Yes, that is true. But at that time, you probably spent too much time on solving the two Bishops against a Knight ending?

"No, that was all background and general use of machines. That was for fun. That was just part time."

You also started some cooperation with Tony Scherzer?

"Yes, we talked a couple of times and visited each other a couple of times and out of it I designed a new move generator which is still, I think, really good. It is a full move generator. One piece of hardware where you just hand in the last move and it drops out the next move. There are no iterations, there are no half moves, and no half cycles. Just give it the last move and it flows through logic and probably can do it in a ten millionth of a second. It is still unbuilt.

"I started the design and I polished it up a couple of times and tried to fit it into a programmable logic. Probably in the next generation it will fit in programmable logic. You know, talking about xylinx or these type of chips, just blank chips where you put in logic equations. Those chips are getting very large and probably in one or two generations I will be able just to down load it to programmable hardware."

At the end of the eighties you had contact with Feng-hsiung Hsu.

"Yes, I was on his Ph.D. thesis committee. It was fun to do."

Constructing the endgame databases is in some sense related to constructing problems.

"Yes, BELlE once published a mate problem, with 5 pieces. What I did is look for 5-pieces lined up in various forms on the board and looked at the initial positions. Then I chased down prime variations and made sure there were no cooks, and no doubles. I found maybe a dozen of them, and then I looked manually at these dozen positions and selected the prettiest one. Anyway, it was published under the name BELLE and I think it is still the only computer-generated problem that I have seen published."

Considering the influence of chess programs on humans, to what level may the human playing strength raise?

"I do not know. In a real ELO sense it is really hard to measure the top players. It is not significant. They get ratings by beating weaker players and that is not a valid way to rate players. So it is only valid to rate them in the centre. I believe that the ELO rating is correct and they will get those expectancies from the lower rated players. I think that if there were a whole spectrum of stronger players above them that their rating would actually be much higher, right now. They play stronger than $2750 \mathrm{I}$ think. They still get the expectancy. I probably believe it will be pushed up to around 3000 . Fischer and Kasparov, I believe, are really 2800 , at least in their heydays and they could probably be pushed a 100 points maybe $200 . "$

Speaking of the ELO rating, I know from Frederic Friedel that you once have suggested a new rating system for the PCA.

"I did the PCA rating system, I knew nothing about ratings and I read the ELo stuff and I heard indirectly what FIDE does about the various problems and aspects of it. I listened to everything and did what I thought was right. It is a good rating system. I think it works. It has less inflation and lesser problems than many other rating systems. It is more tuned with instant calculations by computers. You put the results in the computers during the tournament and you get new results. We update the ratings biweekly or monthly, a really quick turn around. I hope something like this is maintained, in the future, after the reconciliation of FIDE and PCA."

Sixteen years ago you were in favour of the Shannon-A type of strategy. What is your position now?

"Probably for the same reason as with the database construction, with Shannon A you never have to say you are sorry. I do not think you are going to get in an error rate near zero. Therefore, you cannot just skip something and never look at it. The practice is to have a variable depth tree. You can look deeper at some spots. But if you put an order of magnitude more work into the tree it should be a proper superset of the previous tree. Everything should be deeper if you put a lot more work into it. In that sense, it is Shannon A and nothing is thrown away beforehand."

Are you aware of the thesis of Aske Plaat on SSS* and on $\alpha-\beta$ minimal window' search with transposition tables?

"No, not specifically. I have not seen it yet." 
Could you tell something on creativity and computers?

"I think computers are very unique. They are original thinkers. What could be more original than teaching how pieces move, and generating all 5-piece endgames. It is all knowledge. There is nothing more in that small corner of the world. When BELLE was playing tournaments in the early 1980s I always sent the tournament games to Berliner. Berliner commented on them and he returned them. In almost every tournament he pointed to a game or two and said that he had never seen a particular concept before. He is very experienced with chess and stated: "I have never seen the idea before." Sometimes, it was a kind of interference. Sometimes it was a total original idea. It might happen because people think the way they are taught and in their experiences they come up with people who are taught out of the same books they have been. Computers are original, they are not constrained that way. So I think computers are more original, not as deep maybe, but more original than humans."

\section{How about intuition?}

"I do not understand. I do not know what intuition is. It is another word for being deeper than you have a right to be. Everyone has intuition in some chess sense or has intuition to sacrifice something. If they lose they say alright I thought maybe there was something there and if they win it is intuition [laughter]. It is deeper than they can really calculate."

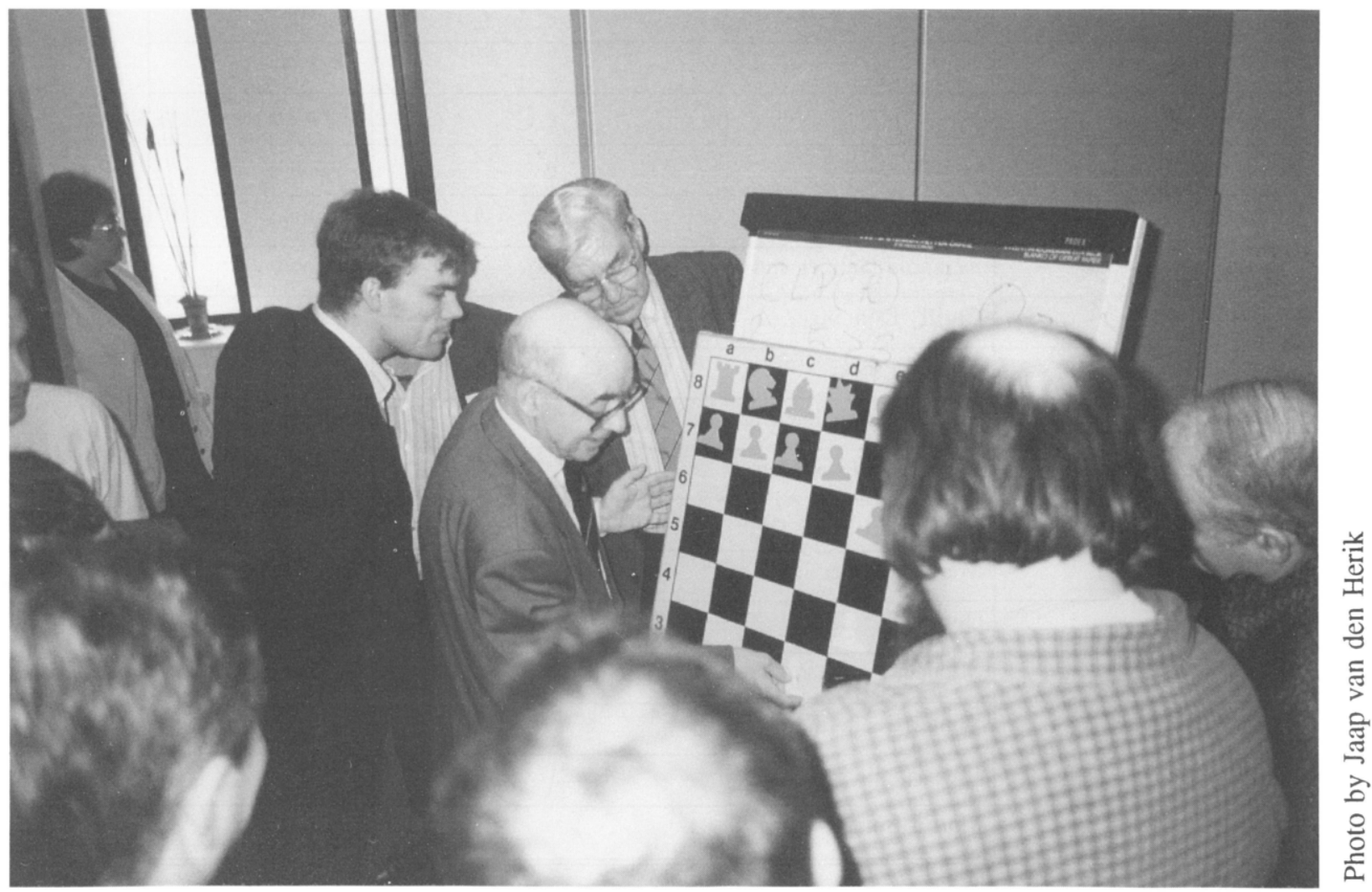

THE SCORCERER'S APPRENTICE PROVIDING THE POST-MORTEM ANALYSES

Grandmaster Bronstein showing his thoughts to the audience.

Vaeshartelt, Maastricht, June 27, 1996. 